DOI: 10.17707/AgricultForest.61.1.27

\author{
Abdullah SESSIZ, Resat ESGICI, \\ Gültekin ÖZDEMIR, A.Konuralp ELIÇIN, F.Göksel PEKITKAN ${ }^{I}$
}

\title{
CUTTING PROPERTIES OF DIFFERENT GRAPE VARIETIES
}

\begin{abstract}
SUMMARY
This study was conducted in order to determine the cutting properties such as cutting force, cutting strength, cutting energy of different wine grape branch (cutting) as fonction of moisture content, diamter and variety. The cutting properties were measured at three moisture content levels (35.2, 42.4, and $46 \%$ ), four cross-section area $\left(12.56,28.27,50.26\right.$ and $\left.78.54 \mathrm{~mm}^{2}\right)$ and eight wine grapes varieties (Tannat, Merlot, Cot, Chardonnay, Viognier, Cabernet Sauvignon, Shiraz, Cabarnet Franc). The results indicated that cutting force, cutting strength and cutting energy requirement varied from variety to variety. The maximum cutting force, cutting strength and cutting energy were obtained at Cabernet Franc grape variety as 1397.60 N, $21.68 \mathrm{MPa}$ and 3.68 J, respectively. Followed by varieties Shiraz, Cabernet, Viognar Chardonnay, Cot, Merlot and Tannat, respectively. The minimum cutting force, cutting strength and cutting energy were obtained at Tannat grape variety as $981.65 \mathrm{~N}, 13.94 \mathrm{MPa}$, and 2.39 $\mathrm{J}$, respectively. This effect could be related to higher stem wall thickness and cross-sectional area of Cabernet Franc compared to the other examined varieties.

Therefore, the obtained data of cutting properties of grape branches are very important for the response of branch to the agricultural operation.
\end{abstract}

Keywords: Cutting strength, grapevine, pruning machine design, vineyard

\section{INTRODUCTION}

Turkey is one of the main producers of grapes in the world. It is at sixth rank in grape production with 4 million ton and 550.000 ha production area. It is the biggest exporter of raisin grapes. Each year over 200.000 tons golden coloured raisins is exported all over the world. The grape export is 170.000 ton valued at 133 million \$ (Uzun and Bayır, 2008).

Mechanization of agriculture particularly after harvest has been produced big demand on the knowledge of physical and mechanical properties of products.

\footnotetext{
1 Abdullah SESSİZ, (corresponding author: asessiz@dicle.edu.tr), Resat ESGİCİ, A. Konuralp ELIÇCiN, F. Göksel PEKITKKAN, Faculty of Agriculture, Department of Agricultural Machinery, Dicle University, Diyarbakır, Gültekin ÖZDEMIR, Faculty of Agriculture, Department of Horticultural, Dicle University, Diyarbakır, TURKEY. Paper presented at the $5^{\text {th }}$ International Scientific Agricultural Symposium "AGROSYM 2014". Notes: The authors declare that they have no conflicts of interest. Authorship Form signed online.
} 
These properties depend on the species, variety, diameter, maturity, moisture content and cellular structure (Persson, 1987; Nazari Galedar et al., 2008). The variation in the physical properties of plant stalks and the resistance of cutting equipment have to be known in order to understand the behavior of material with respect to different operation of conditions. Knowing those properties will be useful for both manufacturers and consumers of food processing equipment. Especillay, information on plant properties and the power or energy requirement of equipment has been very valuable for selecting design and operational parameters (Persson, 1987; Emadi et al., 2004; Voicu et al., 2011; Ghahraei et al., 2011; Hoseinzadeh and Shirneshan, 2012). Perhaps, the stem of plants cutting energy is one of the main parameters for optimizing design of cutting elements in harvesting and pruning machines (Alizadeh et al., 2011). Therefore, comparative performance of cutting elements applied in harvester and pruning machine design can be judge by their cutting energy requirements, cutting force and stress applied (Chakraverty et al., 2003; Alizadeh et al., 2011).

Cutting strength and cutting energy are related to the stem mechanical and physical properties. Therefore, such information is very important for the suitable design of grape pruning knife and pruning machine and harvesters for efficient use of energy.

The objective of this study was to determine the cutting properties (cutting force, cutting strength and cutting power requirement and cutting energy) for eigth different wine grape depending on moisture content and cross-sectional area.

\section{MATERIAL AND METHODS}

Sample preparation and measuring apparatus

This study was carried out in the Agricultural Machinery Department, Agriculture Faculty, Dicle University, Diyarbakir, Turkey. Eight wine grapes varieties, namely Tannat, Merlot, Cot, Chardonnay, Viognier, Cabernet Sauvignon, Shiraz and Cabarnet Franc were selected for cutting properties in the experiment. For doing cutting test, sample of grape branches were obtained from Mezopotamia (commercial farm) Vinyard in Diyarbakır Province (Figure 1). The experiment tests were performed during grape pruning season in 2012 year.

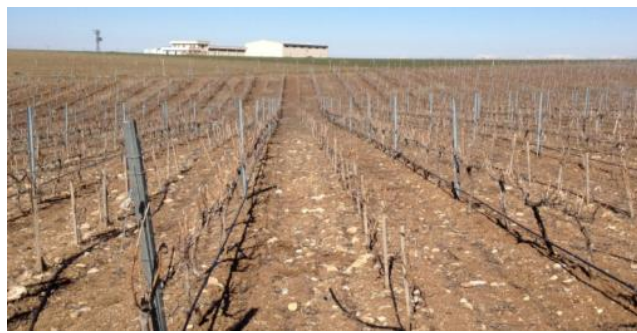

Figure 1. Experimental Farm Vinyard.

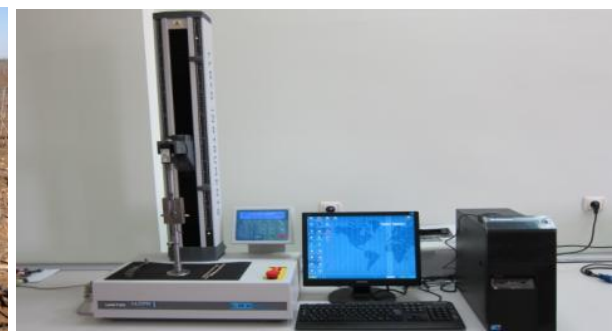

Figure 2. Instron universal testing Machine. 
Specimens were keeped in the refrigerator at temrature $4^{\circ} \mathrm{C}$ in laboratory of Agricultural Machinery Department. In order to determine the initial moisture content was determined by using the flowing equation (ASAE, 2006; Alizadeh at al., 2011). In order to determine the initial moisture content, three samples $30 \mathrm{~g}$ were weighed and dried in an oven of $105^{\circ} \mathrm{c}$ for $24 \mathrm{~h}$ and then reweighed. The moisture content was determined by using the following equation (ASAE, 2006; Alizadeh et al., 2011).

$$
\mathrm{MC}=\frac{\mathrm{SB}-\mathrm{SA}}{\mathrm{SB}} \mathrm{x} 100
$$

Where:

SB : Sample mass before drying, g.

SA : Sample mass after drying, g.

The moisture content levels were determined as $35.4 \%, 42.4 \%$ and $46 \%$ w.b. The experiment results were evaluated according these moisture content values.

Determination of mechanical properties

The Lloyd LRX plus materials testing machine (Figure 2) was used to measure the cutting force and cutting energy. The cutting speed of the machine, $100 \mathrm{~mm} / \mathrm{min}$, was used for all tests

The cutting strength was measured in double shear using a shear apparatus. The maximum shearing strength of the grape branches were determined by dividing the shearing force into two section areas of the branches sides as Equation (Mohsenin 1980; Beyhan 1998; Sessiz 2003; Amer Eissa et al. 2008; Zareiforoush et al. 2010)

$$
S \sigma=\frac{F m a}{2 \mathrm{~A}}
$$

Where: $\sigma s$ is the maximum cutting strength in (MPa), $F_{\max }$ is the maximum cutting force in $(\mathrm{N})$ and $A$ is the cross-sectional area of cane in $\left(\mathrm{mm}^{2}\right)$.

Cutting energy was calculated by measuring the surface area under the cutting force-deformation curve (Heidar and Chegini, 2011; Chen et al., 2004; Nazari Galedar et al., 2008; Zareiforoush et al., 2010). The cutting energy and displecment was calculated, by Instron universal testing instrument, of the area under the curve with the help of the force and displacement data by using a NEXYGEN computer program.

From cutting energy data, specific cutting energy was determined by following equation (Heidar and Chegini 2011).

$$
\mathrm{Esc}=\frac{\mathrm{Ec}}{\mathrm{A}}
$$

Esc: Specific cutting energy, $\mathrm{J} / \mathrm{mm}^{2}$

Ec: Cutting energy, J

A: Cross-section area, $\mathrm{mm}^{2}$

Experimental design and statistical analysis 
The experimental results were tested using standard variance analysis (ANOVA) for the randomized complete block design. Cutting properties were determined with 3 replications in each treatment of the canes. Mean seperations were made for significant effecets with LSD and the means were compared at the $1 \%$ and $5 \%$ levels of significance using the Tukey multiple range tests in JAMP software.

\section{RESULTS AND DISCUSSION}

The effect of grape varieties on cutting force, cutting strength and cutting energy are presented in Table 1. Variance analysis and result of tukey test show that the difference between varieties were found significant $(\mathrm{p}<0.05)$. The results indicated that cutting force, cutting strength and cutting energy requirement varied from variety to variety. The maximum cutting force, cutting strength and cutting energy were obtained at Cabernet Franc grape variety as $1397.60 \mathrm{~N}$, $21.68 \mathrm{MPa}$ and $3.68 \mathrm{~J}$, respectively. Followed by varieties Shiraz, Cabernet, Viognar Chardonnay, Cot, Merlot and Tannat, respectively. The minimum cutting force, cutting strength and cutting energy were obtained at Tannat grape variety as $981.65 \mathrm{~N}, 13.94 \mathrm{MPa}$, and $2.39 \mathrm{~J}$, respectively. This effect could be related to higher stem wall thickness and cross-sectional area of Cabernet Franc compared to the other examined varieties.

The average cutting strength of Cabarnet Franc was about 1.5 time's greater thanTannat variety. There were big differences among varieties in to terms of cutting force, cutting strength and cutting energy. Tukey test results (Table 1) shows that shear strength and cutting energy between Viognier, Cabernet Sauvignon and Shiraz varieties in \%5 level has not significant difference. This side, there was not found significant different between Chardonnay and Cot. The values of Tannat and Merlot shows that the similar properties and there was not found difference tehese varieties as statistically (Table 1). This difference is due to different physical, mechanical and physiological properties of stem varieties (Esehaghbeygi et al., 2009; Hoseinzadeh and Shirneshan, 2012). These informations are very valuable for selecting suitable equipment design. Selection of suitable cutting apparatues and equipment plays an important role economizing on cutting force requirement. So, we must consider such as grape variety, variety stem diameter, physical and mechanical properties.

As can be seen from the table, the maximumum strength was obtained at Cabernet Franc variety, while the minimum cutting strength was obtained at Tannat and Melot varieties. The maximum values of cutting energy were found at Cabarnet Franc variety. Variety Tannat is observed less cutting energy, when compared to the rest of varieties.

The results of Tukey tests showed that there were found significant difference between mean values of cutting energy from variety to variety. The grape variety Cabernet Franc is approved as the strongest, but the variety Tanna, Merlot and Cot as the weakest material in shear cutting. These studies showed 
that cutting energy is related to the stem physical and mechanical properties.When designing a pruning machine, we should consider these properties.

Table 1: The relationship between average cutting properties and grape varieties

\begin{tabular}{lccc}
\hline Grape varieties & $\begin{array}{c}\text { Cutting Force } \\
(\mathrm{N})\end{array}$ & $\begin{array}{c}\text { Cutting Strength } \\
(\mathrm{MPa})\end{array}$ & $\begin{array}{c}\text { Cutting } \\
\text { Energy }(\mathrm{J})\end{array}$ \\
\hline Tannat & $981.65^{\mathrm{d}^{*}}$ & $13.94 \mathrm{~d}$ & $2.39 \mathrm{e}$ \\
Merlot & $1011.97^{\mathrm{d}}$ & $13.98 \mathrm{~d}$ & $2.64 \mathrm{de}$ \\
Cot & $1049.65^{\mathrm{cd}}$ & $14.29 \mathrm{~cd}$ & $2.90 \mathrm{~cd}$ \\
Chardonnay & $1145.06^{\mathrm{bc}}$ & $15.83 \mathrm{bc}$ & $3.05 \mathrm{bcd}$ \\
Viognier & $1158.07^{\mathrm{b}}$ & $16.13 \mathrm{~b}$ & $3.334 \mathrm{abc}$ \\
Cabernet sauvignon & $1166.68^{\mathrm{b}}$ & $16.47 \mathrm{~b}$ & $3.386 \mathrm{ab}$ \\
Shiraz & $1214.42^{\mathrm{b}}$ & $16.55 \mathrm{~b}$ & $3.481 \mathrm{ab}$ \\
Cabarnet Franc & $1394.60^{\mathrm{a}}$ & $21.68 \mathrm{a}$ & $3.686 \mathrm{a}$ \\
\hline Mean & 1140.25 & 16.11 & 3.11 \\
\hline LSD & 97.88 & 1.744 & 0.472 \\
\hline
\end{tabular}

* Means followed by the same letter in each column are not significantly different by Tukey multiple range test at the $5 \%$ level.

\section{CONCLUSIONS}

In this study, the cutting properties of eigth different grape varieties were experimentally investigated. The average cutting strength varied between 13.94 MPa-21.68 MPa. The cross-section area and moisture content of grape cane has significant influence on cutting force, cutting strength and cutting energy. Cutting energy values varied from $2.39 \mathrm{~J}-3.68 \mathrm{~J}$. Also, results showed that the average cutting force, cutting strength and cutting energy of Cabernet Franc variety were significantly higher than rest of the varieties. The data obtained from the cutting tests of grape canes can be used in the design and development of an experimental prototype cutting machine.

\section{ACKNOWLEDGEMENTS}

This study was supported by Scientific Research Funding (DÜBAP-08ZF-59) of Dicle University. The authors would like to thanks the University of Dicle, Scientific Research Funding for financial support for this Project.

\section{REFERENCES}

Alizadeh, M.R., F.R.Ajdadi, A. Dabbaghi, 2011. Cutting energy of rice stem as influenced by internode position and dimensional characteristics of different varieties. AJCS 5(6):681-687, ISSN:1835-2707.

Amer Eissa, A.H., A.H. Gomaa, M.H. Baiomay, A.A. Ibrahim, 2008. Physical and mechanical charactesristics for some agricultural residues. Misr $J \mathrm{Ag}$ Eng 25(1):121-146.

ASAE Standards, 2006. S358.2: 1:1 Measurement -Forages. 52nd edn. American Society of Agricultural Engineers, St Joseph MI. 
Beyhan, M.A., 1996. Determination of shear strength of hazelnut sucker. J.Agric.Fac.OMU 11(3): 167-181.

Chakraverty, A., P.R. Singh, G.S.V. Raghavan, H.S. Ramaswamy, 2003. Handbook of postharvest technology. 1st edn, Marcel Dekker Inc, New York.

Emadi, B.Ş., V. Kosse, P. Yarlagadda, 2004. Relationship between mechanical properties of pumpkin and skin thickness. International Journal of Food Properties 8(2), 277-287.

Esehaghbeygi, A., B. Hoseinzadeh, M. Khazaei, M. Masoumi, 2009. Bending and shearing properties of wheat stem of alvand variety. World Appl Sci J For 6: 1028-1032.

Ghahraei. O.D., A. Ahmad, H. Khalina, J. Othman, 2011. Cuttıng tests of kenaf stems. Transactions of the ASABE Vol. For 54(1): 51-56.

Heidari, A. and G.R.Chegini, 2011. Determining the shear strength and picking force of rose flower. Agricultural Engineering ejpau For 14(2): 13. Available Online: http://www.ejpau.media.pl/volume14/issue2/art-13.html.

Hoseinzadeh, B. and A. Shirneshan, 2012. Bending and shearing characteristics of canola stem. American-Eurasian J. Agric. \& Environ Sci For 12 (3): $275-281$.

Mohsenin, N.N., 1980. Physical properties of plant and animal materials. New York, Gordon and Breach Publishers.

Nazari, G.M., A. Tabatabaeefar, A. Jafari, A. Sharifi, S. Rafiee, 2008. Bending and Shearing Characteristics of Alfalfa Stems. Agricultural Engineering International the CIGR Ejournal. Manuscript FP 08 001. Vol. X. May.

Persson, S., 1987. Mechanics of cutting plant material. ASAE Publications, Michigan.

Sessiz, A., 2003. Physical and mechanical properties of soybean crops and their relationship. Indian Journal of Agricultural Engineering For 40(2): 30-38, New Delhi, India.

Uzun, İ. and A. Bayır, 2008. Viticulture in Turkey bulletin UASVM, Horticulture 65(1),ISSN 1843-5254; ISSN 1843-5394.

Voicu, G., E. Moiceanu, M. Sandu, I.C. Poenaru, P. Voicu, 2011. Experiments regarding mechanical behaviour of energetic plant miscanthus to crushing and shear stress. Engineering For Rural Development Jelgava, 26.27.05.2011.

Zareiforoush, H., S.S. Mohtasebi, H. Tavakoli, M.R. Alizadeh, 2010. Effect of loading rate on mechanical properties of rice (Oryza sativa L.) straw. Aust J Crop Sci For 4(3): 190-195. 